\title{
Hafnia-Silica Cryogels: Solvent-Assisted Textural and Catalytic Control in the Citronellal Cyclization
}

\author{
Ciril Jimeno, ${ }^{*[a]}$ Jonathan Miras, ${ }^{[b]}$ and Jordi Esquena ${ }^{[b]}$
}

\begin{abstract}
A series of hafnia-silica mixed oxides of $\mathrm{HfO}_{2}\left(\mathrm{SiO}_{2}\right)_{8}$ stoichiometry were prepared by a sol-gel method followed by freezedrying. Two hafnium precursors, $\mathrm{Hf}(\mathrm{OiPr})_{4}$ and $\mathrm{Hf}(\mathrm{OtBu})_{4}$ were examined under a variety of aqueous-alcoholic systems. A decisive dependence of the alcoholic solvent on the gel formation and the surface and porosity of the final materials was found, which in turn were key to the enhancement of catalysis. Hence, acid hydrolysis and gelification of $\mathrm{Hf}(\mathrm{OiPr})_{4}$ in tert-butyl alcohol, followed by lyophilization, yielded a material with the
\end{abstract}

\section{Introduction}

In continuation of our efforts to find suitable $\mathrm{MO}_{2}-\mathrm{SiO}_{2}$ mixed oxides as catalysts for the carbonyl-ene reaction, ${ }^{[1]}$ we naturally turned our attention to $\mathrm{HfO}_{2}-\mathrm{SiO}_{2}$ co-gels after having evaluated the more common titania-silica and zirconia-silica mixed oxides. ${ }^{[2]}$ However, in spite of the high coordination number of $\mathrm{Hf}$ (from 6 to 8, like Zr) and its potential as Lewis acid according to its similarities to $\mathrm{Zr}^{\mathrm{lv}}$, hardly a few examples were found in the literature of applications in heterogeneous catalysis. In this context we mention the use of sulfated-hafnia-promoted zirconia in $n$-butane isomerization. ${ }^{[3]}$ Pure hafnia was also evaluated in the $\mathrm{H}_{2} \mathrm{O}_{2}$ decomposition, ${ }^{[4]}$ and gas-phase studies recently demonstrated the potential of hafnium oxide cations in oxidation reactions. ${ }^{[5]}$ We are not aware of any further direct catalytic application of hafnium oxide, and none of them refers to catalytic $\mathrm{C}-\mathrm{C}$ bond forming processes such as the carbonylene reaction.

On the other hand there is an obvious interest in embedding hafnia in silica to facilitate its dispersion and, therefore, increase the surface area of the material, which is ideal for catalysis. $\mathrm{HfO}_{2}-\mathrm{SiO}_{2}$ mixed oxides have been synthesized and studied before, but especially for their application in microelectronics, ${ }^{[6]}$ optics, ${ }^{[7]}$ or in toughened ceramics. ${ }^{[8]}$ Remarkable meth-

\section{[a] Dr. C. Jimeno}

Department of Biological Chemistry and Molecular Modelling

Institute of Advanced Chemistry of Catalonia (IQAC-CSIC)

c/Jordi Girona 18-26, E08034, Barcelona (Spain)

Fax: $(+34)$ 93-2045904

E-mail: ciril.jimeno@iqac.csic.es

[b] J. Miras, Dr. J. Esquena

Department of Chemical and Biomolecular Nanotechnology Institute of Advanced Chemistry of Catalonia (IQAC-CSIC) and CIBER de Bioingeniería, Biomateriales y Nanomedicina (CIBER-BBN) C/Jordi Girona 18-26, E08034, Barcelona (Spain)

Supporting information for this article is available on the WWW under http://dx.doi.org/10.1002/cctc.201402189. highest mesoporosity and specific surface area. This catalyst behaved most efficiently in the acid-catalyzed cyclization of citronellal to isopulegol at room temperature. Furthermore, this cryogel also presented combined Lewis acidity and hydrogen bonding that resulted in higher diastereoselectivity for the above reaction. These results highlight the effect of how the textural and, therefore catalytic, properties of the cryogels depend decisively on the solvents chosen for their synthesis.

ods for the preparation of hafnia-silica thin films comprise the use of organic-inorganic hybrid precursors in sol-gel methods involving copolymerization of organically modified oxohafnium complexes with modified alcoxysilanes. ${ }^{[9]}$ Hafnia-silica thin films can also be obtained by electron-beam deposition. ${ }^{[10]}$ $\mathrm{HfO}_{2}\left(\mathrm{SiO}_{2}\right)_{4}$ materials of this specific stoichiometry were prepared from single precursors by gelation of hafnium-silyloxy complexes. ${ }^{[11]}$ Nevertheless, hafnia-silica mixed oxides can also be obtained more typically by conventional sol-gel methods, by co-hydrolysis and gelation of tetraethyl orthosilicate (TEOS) with the appropriate $\mathrm{Hf}^{\mathrm{f}}$ precursor. ${ }^{[12]}$

The scarcity of results in catalysis and the potential of hafnia thus spurred our research. Accordingly, we decided to prepare and evaluate a series of $\mathrm{HfO}_{2}-\mathrm{SiO}_{2}$ mixed oxides in the citronellal cyclization, a carbonyl-ene reaction that yields industrially relevant isopulegol. ${ }^{[13]}$ The catalysts were prepared by proven sol-gel methods, and the final dry gels were obtained by freeze-drying in view of the high specific surface areas obtained for $\mathrm{TiO}_{2}-\mathrm{SiO}_{2}$ and $\mathrm{ZrO}_{2}-\mathrm{SiO}_{2}$ before ${ }^{[2]}$ and the mild conditions required. $\mathrm{MO}_{2}-\mathrm{SiO}_{2}$ cryogels are not intended for hightemperature reactions but for reactions that can be performed at approximately ambient conditions, as it is the case in the present study.

\section{Results and Discussion}

\section{Preparation and characterization of hafnia-silica cryogels}

The preparation of the $\mathrm{HfO}_{2}-\mathrm{SiO}_{2}$ mixed oxides by the sol-gel method was the source control of the textural and acidic properties of the final materials, which was a requirement for catalysis. ${ }^{[14]}$ The gels were synthesized by co-hydrolysis of TEOS and the appropriate hafnium precursor in aqueous hydrochloric acid. After $24 \mathrm{~h}$ of hydrolysis, samples were heated at $80^{\circ} \mathrm{C}$ in 
closed bottles, at which temperature gelation occurred. Finally, solvents from the samples were removed by lyophilization. Hf$(\mathrm{O} i \mathrm{Pr})_{4} \cdot \mathrm{PrOH}$ and $\mathrm{Hf}(\mathrm{OtBu})_{4} \cdot \mathrm{BuOH}$ were evaluated as precursors in a variety of alcoholic solvents suitable for freeze-drying: ethanol, isopropyl alcohol, and tert-butyl alcohol proved suitable for obtaining $\mathrm{HfO}_{2}\left(\mathrm{SiO}_{2}\right)_{8}$ co-gels, but phase separation and precipitation occurred if more concentrated hafnia samples, that is, $\mathrm{HfO}_{2}\left(\mathrm{SiO}_{2}\right)_{4}$, were attempted. ${ }^{[12 a, b]}$ Finally, ethylene glycol was also used with success, yielding gels much faster (a few hours) than the other alcohols. This solvent cannot be lyophilized, though, and must be removed by calcination.

From a visual standpoint, no monoliths were obtained in any case, and a different degree of breaking and shrinkage was clearly depending on the samples. Materials prepared in $t \mathrm{BuOH}$ consisted of bigger, more voluminous, and lighter pieces than those made in $\mathrm{iPrOH}$, which in turn were more voluminous than those made in $\mathrm{EtOH}$ or ethylene glycol.

All the obtained xerogels were amorphous as determined by $X$-rays diffraction (see the Supporting Information), and their textural and porosity characteristics were established by nitrogen sorption measurements. Results are shown in Table 1. The used for their calculation. This was reflected in an increase of the total pore volume up to $1.06 \mathrm{~cm}^{3} \mathrm{~g}^{-1}$ for Hf-Si8-C. An increase in SSA if moving from ethanol to tert-butyl alcohol as the solvent was also observed if $\mathrm{Hf}(\mathrm{OtBu})_{4}$ was used instead of $\mathrm{Hf}(\mathrm{O} i \mathrm{Pr})_{4}\left(336 \mathrm{~m}^{2} \mathrm{~g}^{-1}\right.$ for Hf-Si8-E and $558 \mathrm{~m}^{2} \mathrm{~g}^{-1}$ for Hf-Si8-F), although these samples contained more micropores. Again, tert-butyl alcohol also provided a more porous material, achieving $V_{\text {total }}$ of $1.25 \mathrm{~cm}^{3} \mathrm{~g}^{-1}$ for Hf-Si8-F.

Hf-Si8-D was a different case because the use of ethylene glycol as the solvent for its preparation impeded the application of the freeze-drying technique. The xerogel was obtained by calcination nevertheless, and its textural characterization showed that high SSA was also obtained. However, microporosity was high as well, with pore properties similar to those obtained with ethanol. Therefore ethylene glycol can be considered a convenient substitute for ethanol in the sol-gel process because it yields gels much faster with similar results.

In Figure 1, the nitrogen sorption isotherms are depicted for compounds $\mathrm{Hf}-\mathrm{Si8}-\mathrm{A}$ to $\mathrm{C}$, which reflect the observed increase in SSA and mesoporosity if changing from $\mathrm{EtOH}$ to $\mathrm{iPrOH}$ and to $t \mathrm{BuOH}$ as solvents for the preparation of the cryogels. The isotherms for the other three xerogels are shown in the Supporting Information. In Figure 2, the pore-size distributions according to the Barrett-Joyner-Halenda (BJH) and the DFT methods are shown. The BJH method yielded a monomodal distribution of mesopores centered at $\mathbf{\square}$ pore diameters of $3.4,3.6$, and $4.9 \mathrm{~nm}$ for Hf-Si8-A, B, and C, respectively (Figure $2 \mathrm{~A}$ ). However, this method is limited by porosity and does not extend to pores of less than $3 \mathrm{~nm}$ in diameter. hafnia-silica mixed oxides are named as $\mathrm{Hf}-\mathrm{Si}$ - $\mathrm{X}$, where $\mathrm{Hf}-$ Si8 stands for their molar composition and $\mathrm{X}$ is a letter added to differentiate the method of synthesis, also shown in Table 1. At first sight, it was clear that the alcoholic solvent had a decisive impact on the specific surface area (SSA) and porosity of the materials. SSA increased markedly from $\mathrm{Hf}-\mathrm{Si8}-\mathrm{A}$ (466 $\mathrm{m}^{2} \mathrm{~g}^{-1}$ in ethanol) to $\mathrm{Hf}-\mathrm{Si} 8-\mathrm{B}\left(604 \mathrm{~m}^{2} \mathrm{~g}^{-1}\right.$ in isopropyl alcohol) and to Hf-Si8-C $\left(684 \mathrm{~m}^{2} \mathrm{~g}^{-1}\right.$ in tert-butyl alcohol), with concomitant decrease in the surface owing to microporosity. It is clear that the more microporous materials were those prepared in $\mathrm{EtOH}$ ( $41 \%$ of the surface area owing to microporosity for $\mathrm{Hf}-\mathrm{Si} 8-\mathrm{A}$ and $43 \%$ for $\mathrm{Hf}-\mathrm{Si} 8-\mathrm{E})$ followed closely by $\mathrm{Hf}-\mathrm{Si} 8-$ D (prepared in ethylene glycol, $39 \%$ of the surface area owing to microporosity). In contrast, the cryogel prepared in $\mathrm{tBuOH}$ ( $\mathrm{Hf}-\mathrm{Si} 8-\mathrm{C})$ barely reached $9 \%$ microporosity, and the cryogel made in isopropyl alcohol (Hf-Si8-B) had only $13 \%$ microporosity.

Pore diameters also increased in this series from approximately $2.5-3 \mathrm{~nm}$ to $5-6 \mathrm{~nm}$, independently of the method

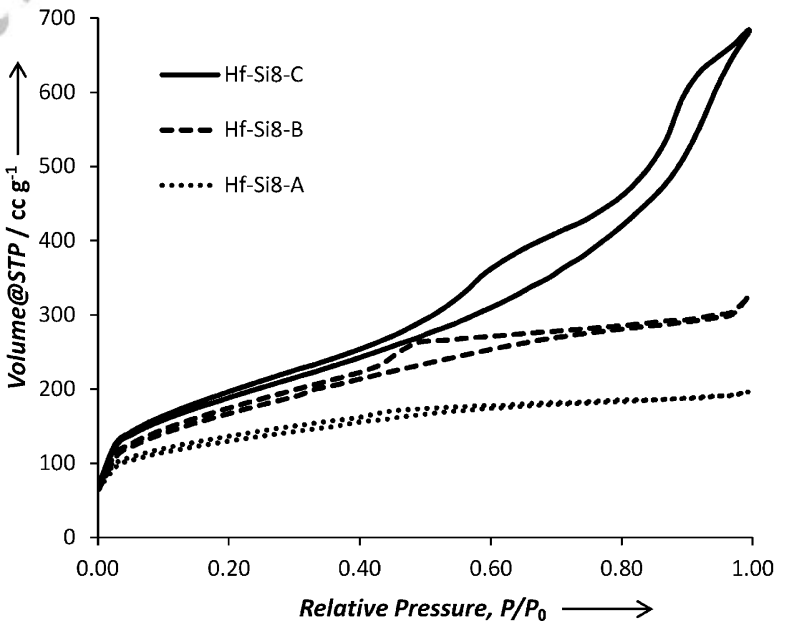

Figure 1. Nitrogen sorption isotherms for cryogels Hf-Si8-A (prepared in ethanol:......), Hf-Si8-B (prepared in isopropyl alcohol:-----) and $\mathrm{Hf}-\mathrm{Si}$-C (prepared in tert-butyl alcohol: - ). STP $=$ Standard temperature and pressure. 

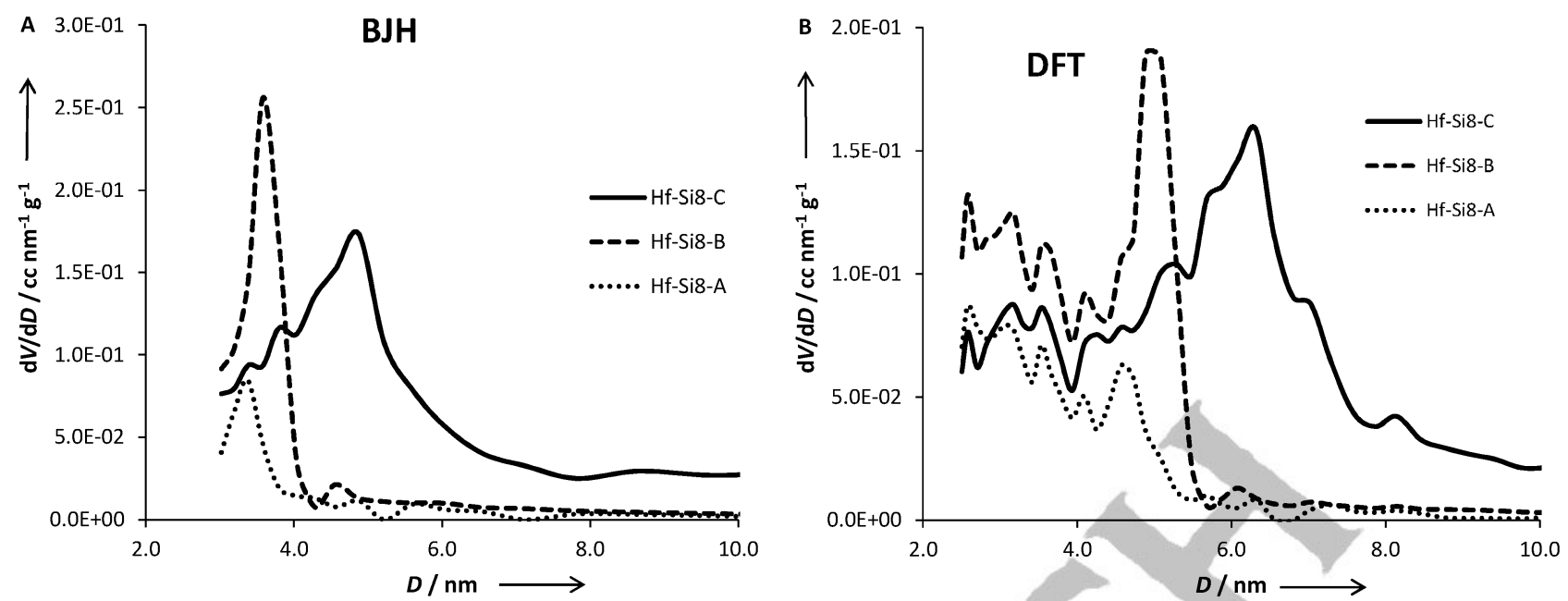

Figure 2. Pore-size distribution according to the A) BJH and B) DFT methods for cryogels Hf-Si8-A (prepared in ethanol: ......), Hf-Si8-B (prepared in isopropyl alcohol: ----) and Hf-Si8-C (prepared in tert-butyl alcohol: - ). $D=\mathbf{\square}$ Pore diameter $\mathbf{\square} \mathbf{\square} \mathbf{d} \mathrm{d} V / \mathrm{d} D$ on y axis ok? $\mathbf{\square}$

Mesopores starting at $2.5 \mathrm{~nm}$ diameter could be better analyzed by the DFT method, ${ }^{[15]}$ which revealed a variety of pores in the range of $2.5-8 \mathrm{~nm}$ diameter. Although a monomodal distribution of pores was not present, nevertheless it also showed a high density of mesopores centered at 4.9 and $6.3 \mathrm{~nm}$ for Hf-Si8-B and C, respectively, whereas a poorer distribution was found for the ethanol-based cryogel Hf-Si8-A (Figure $2 \mathrm{~B}$ ).

Finally, the surface morphology and roughness of cryogels $\mathrm{Hf}-\mathrm{Si} 8-\mathrm{A}, \mathrm{B}$, and $\mathrm{C}$ was also characterized by scanning electron microscopy (SEM). Representative images are shown in Figure 3. No significant differences were found between samples of ethanol-based Hf-Si8-A and isopropyl alcohol based $\mathrm{Hf}-$ Si8-B at low magnification ( $x$ 1000 ), which consisted of sharp boulders with clean breaks (Figure 3, A and D). Only at higher magnification $(\times 10000)$, roughness was appreciated in some faces of the boulders and at that point it was clear the increased roughness of $\mathrm{Hf}-\mathrm{Si}$ - $\mathrm{B}$ was attributable to the effect of iPrOH (Figure 3, C vs. F). In contrast, $t \mathrm{BuOH}$-based $\mathrm{Hf}-\mathrm{Si} 8-\mathrm{C}$ consisted of more rounded boulders that often contained big canals, rather than cracks (Figure 3, G and $\mathrm{H}$ ). Roughness was very much increased and extended, including macropores of approx-
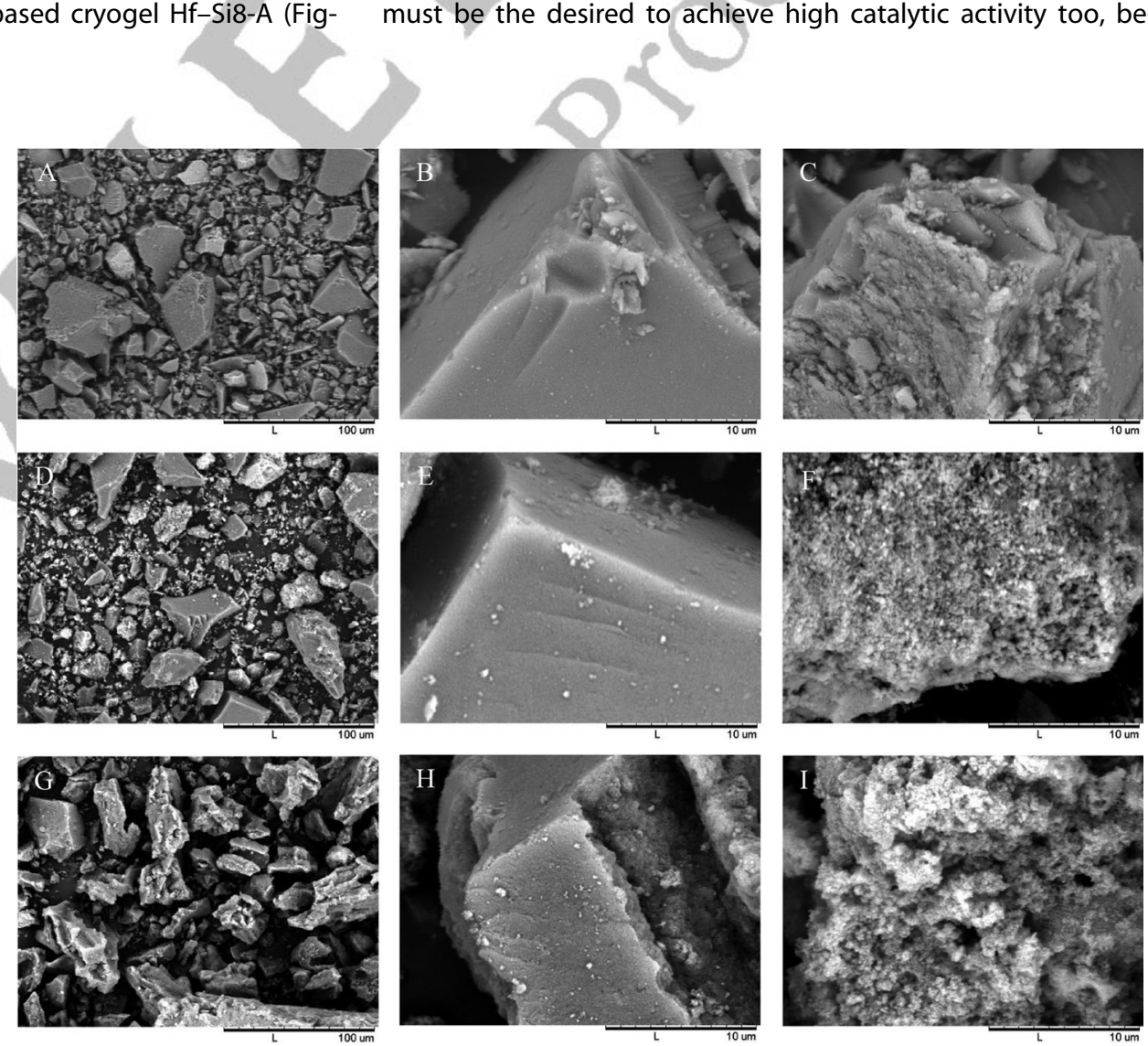

Figure 3. Representative SEM images of $\mathrm{A}-\mathrm{C}$ ) EtOH-based Hf-Si8-A, D-F) iPrOH-based Hf-Si8-B, and G-I) $t \mathrm{BuOH}-$ based $\mathrm{Hf}-\mathrm{Si}$-C. Scale bars $=10(\mathrm{~B}, \mathrm{C}, \mathrm{E}, \mathrm{F}, \mathrm{H}, \mathrm{I})$ and $100 \mu \mathrm{m}(\mathrm{A}, \mathrm{D}, \mathrm{G})$. 
cause the active $\mathrm{HfO}_{2}$ species would be better dispersed and the diffusion of reagents and products to and from the catalytic surface would be greatly improved. It has been recently established that tert-butyl alcohol is very convenient to prepare monolithic silica cryogels because it diminishes pore collapse during lyophilization and thus minimizes shrinkage and breaking. ${ }^{[16]}$ And in line with this, although no monoliths were obtained in our case, bigger, lighter, more porous fragments were always isolated.

\section{Hafnia-silica cryogels as catalysts in the citronellal cycliza- tion to isopulegol}

We tested the set of as-synthesized hafnia-silica xerogels in the citronellal cyclization at room temperature, using $5 \mathrm{~mol} \%$ of $\mathrm{HfO}_{2}$. Besides conversion and chemoselectivity, the stereoselectivity of the reaction towards the desired diastereomer must also be controlled, because four potential products can arise (Scheme 1). Results for conversion and diastereoselectivity ( $d s$ ) are shown in Table 2 . In practice no by-products could be detected arising from potential carbocationic intermediates.

Clearly $\mathrm{iPrOH}$-made catalyst $\mathrm{Hf}-\mathrm{Si}$ - $\mathrm{B}$, and especially $\mathrm{tBuOH}-$ made $\mathrm{Hf}-\mathrm{Si} 8-\mathrm{C}$, were superior to all the other xerogels. In particular, they showed much better performance than ethanolmade $\mathrm{Hf}-\mathrm{Si} 8-\mathrm{A}$ both in conversion and diastereoselectivity, achieving conversions higher than $95 \%$ and $d s$ higher than $74 \%$. Experiments were run by triplicate by using different

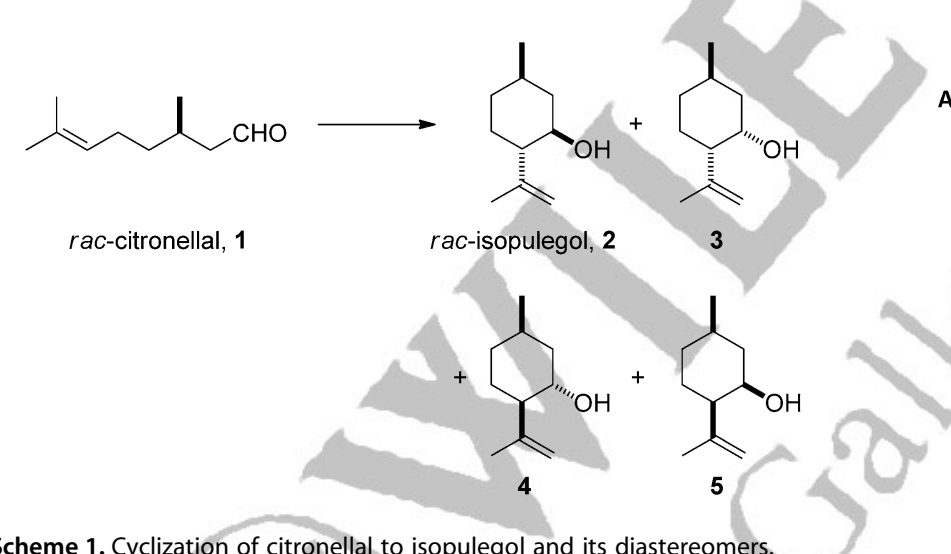

Scheme 1. Cyclization of citronellal to isopulegol and its diastereomers.

Table 2. Results of the citronellal cyclization under $5 \mathrm{~mol} \% \mathrm{HfO}_{2}\left(\mathrm{SiO}_{2}\right)_{8}$ cryogels catalysis.

\begin{tabular}{|c|c|c|c|}
\hline Cryogel & Synthesis conditions & $\begin{array}{l}\text { Conv. }^{[\mathrm{b}]} \\
{[\%]}\end{array}$ & $\begin{array}{l}d s^{[\mathrm{b}]} \\
{[\%]}\end{array}$ \\
\hline $\mathrm{Hf}-\mathrm{Si} 8-\mathrm{A}$ & $\mathrm{Hf}(\mathrm{OiPr})_{4} / \mathrm{EtOH}$ & $62 \pm 10^{[c]}$ & $63 \pm 3^{[c]}$ \\
\hline $\mathrm{Hf}-\mathrm{Si} 8-\mathrm{B}$ & $\mathrm{Hf}(\mathrm{O} i \mathrm{Pr})_{4} / \mathrm{iPrOH}$ & $91 \pm 5^{[c]}$ & $72 \pm 1^{[c]}$ \\
\hline $\mathrm{Hf}-\mathrm{Si} 8-\mathrm{C}$ & $\mathrm{Hf}(\mathrm{OiPr})_{4} / t \mathrm{BuOH}$ & $\begin{array}{l}95 \pm 3^{[c]} \\
95^{[\mathrm{d}]}\end{array}$ & $\begin{array}{l}74 \pm 2^{[\mathrm{c}]} \\
77^{[\mathrm{d}]}\end{array}$ \\
\hline $\mathrm{Hf}-\mathrm{Si} 8-\mathrm{D}^{[\mathrm{a}]}$ & $\mathrm{Hf}(\mathrm{OiPr})_{4} /$ ethylene glycol ${ }^{[a]}$ & 83 & 60 \\
\hline Hf-Si8-E & $\mathrm{Hf}(\mathrm{OtBu})_{4} / \mathrm{EtOH}$ & 41 & 58 \\
\hline $\mathrm{Hf}-\mathrm{Si} 8-\mathrm{F}$ & $\mathrm{Hf}(\mathrm{O} t \mathrm{Bu})_{4} / t \mathrm{BuOH}$ & 55 & 73 \\
\hline
\end{tabular}

[a] Xerogel calcined at $550^{\circ} \mathrm{C}$. [b] Determined from ${ }^{1} \mathrm{H}$ NMR spectroscopy after $20 \mathrm{~h}$. [c] Average of 3 runs with different catalyst batches. [d] Performed at $0{ }^{\circ} \mathrm{C}$ with $10 \mathrm{~mol} \%$ of $\mathrm{Hf}-\mathrm{Si} 8-\mathrm{C}$. batches of catalysts every time, and therefore even the subtle difference between $\mathrm{Hf}-\mathrm{Si}$ - $\mathrm{B}$ and $\mathrm{C}$ could be confirmed statistically. These three cryogels were prepared by using $\mathrm{Hf}(\mathrm{OiPr})_{4}$ as the starting hafnium(IV) source. The same effect could be observed for the pair of cryogels $\mathrm{Hf}-\mathrm{Si8}-\mathrm{E}$ and $\mathrm{F}$, prepared from $\mathrm{Hf}(\mathrm{OtBu})_{4}$. In this case, though, the catalyst made in tert-butyl alcohol, HF-Si8-F, gave lower conversion than $\mathrm{Hf}-\mathrm{Si}$-C, but still a high diastereoselectivity of $73 \%$. The xerogel prepared in ethylene glycol, Hf-Si8-D, gave a good conversion (83\%) but moderate diastereoselectivity, similar to that of ethanol-made catalysts Hf-Si8-A and E. It was thus demonstrated how important the solvent was, in particular, $\mathrm{tBuOH}$, for the preparation of the catalysts, and subsequently for catalyst activity and diastereoselectivity.

Finally, we also performed a reaction at $0{ }^{\circ} \mathrm{C}$ with the best catalyst, $\mathrm{Hf}-\mathrm{Si8}-\mathrm{C}$. Diastereoselectivity increased to $77 \%$, although the catalyst loading had to be increased as well up to $10 \mathrm{~mol} \%$ to achieve the same level of conversion as at room temperature.

It was clear that tert-butyl alcohol, and isopropyl alcohol to a lesser extent, provided catalysts with better performances for the citronellal cyclization. It could be reasonably argued that more porous materials, possessing higher specific surface areas, were obtained with those solvents, and therefore they had higher catalytic activity. This hypothesis was tested by performing a kinetic study with catalysts $\mathrm{Hf}-\mathrm{Si}$ - A, B, and C (Figure 4). First, conversion versus time was measured and the resulting plots confirmed that the observed increase in yield
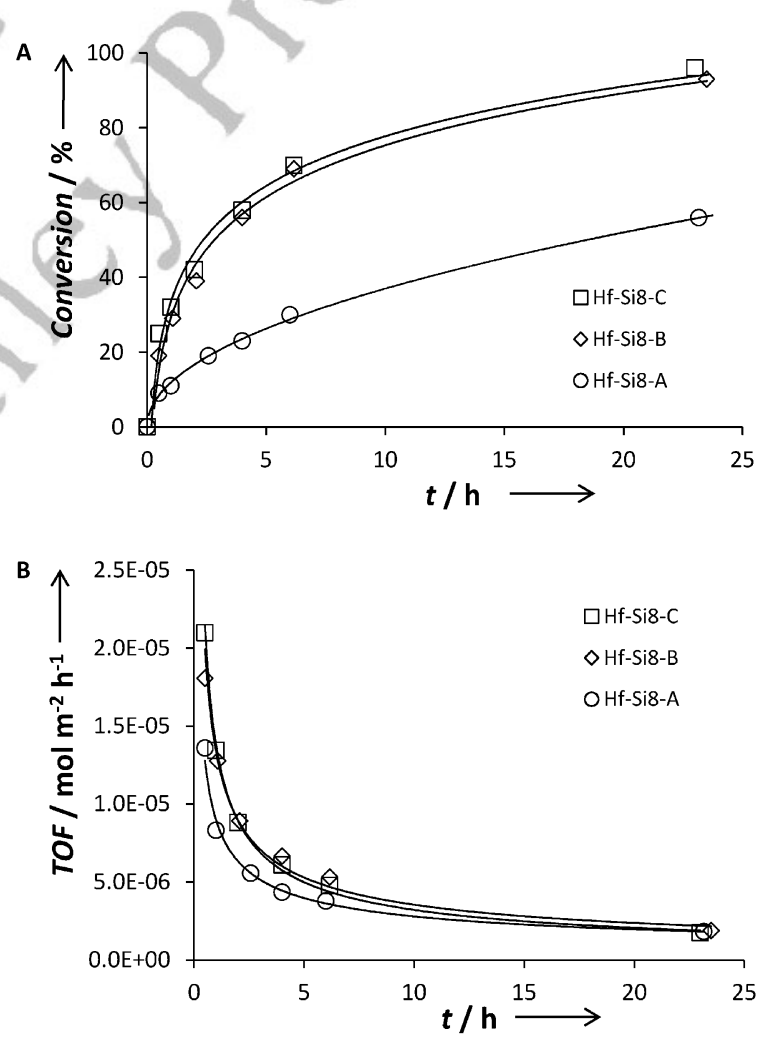

Figure 4. A) Conversion-versus-time plot, and B) TOF-versus-time plot for catalysts Hf-SiO8-A (ethanol-based), Hf-Si8-B (isopropyl alcohol based), and Hf-Si8-C (tert-butyl alcohol based). 
along the studied series of catalysts was attributable to an enhancement of reaction rate (Figure 4, top). Cryogel Hf-Si8-C (prepared in $\mathrm{tBuOH}$ as alcoholic solvent) exhibited fastest conversion, closely followed by $\mathrm{Hf}-\mathrm{Si} 8-\mathrm{B}$ (prepared in $\mathrm{PrOH}$ ), and far away from the activity of EtOH-made catalyst Hf-Si8-A. However, when plotting turnover frequencies (TOF) obtained as moles of citronellal converted per mass of catalyst and its SSA, differences were minimal, if any (Figure 4, bottom). Hf$\mathrm{Si} 8-\mathrm{C}$, and B performed virtually identical, and Hf-Si8-A exhibited slightly lower TOF at shorter reaction times, but the curves converged as the reaction proceeded. Overall, it was thus confirmed that catalytic activity of the studied cryogels depend on their SSA, which was controlled mainly by the solvent used during their synthesis.

\section{Acidity and stereoselectivity}

As we have shown above, the differences in catalytic activity between cryogels could be explained mainly in terms of their SSA. Explaining the differences in diastereoselectivity was a different task. Catalysts prepared with $\mathrm{tBuOH}$ or $\mathrm{iPrOH}$ as alcoholic solvents displayed $d s$ values above $70 \%$, whereas catalysts prepared in $\mathrm{EtOH}$ or ethylene glycol were found at approximately $60 \%$ ds. The acidity of the materials has an important role in catalysis, but also in controlling diastereoselectivity. For example, it was specifically demonstrated how diastereoselectivity in carbonyl-ene reactions was affected by Lewis or Brønsted acidity. ${ }^{[13 c, 17]}$ To understand whether differences in catalyst acidity could affect the diastereoselectivity outcome of the citronellal cyclization, pyridine adsorption FTIR experiments at room temperature were performed with the series of catalysts Hf-Si8-A, B, and C (Figure 5). Regular FTIR spectra of the cryogels Hf-Si8-X are shown in the Supporting Information.

The sharp band at $1445 \mathrm{~cm}^{-1}$ corresponds to vibrations of pyridine adsorbed on both Lewis acid sites and weak Brønsted acid sites (hydrogen-bonded), whereas the broader band at $1539 \mathrm{~cm}^{-1}$ corresponds to protonated pyridine and, therefore, it is associated to pyridine adsorbed on strong Brønsted acid sites. In between, another intense and sharp band centered at $1489 \mathrm{~cm}^{-1}$ arises from interaction with both Lewis and Brønsted acid sites. The band at $1598 \mathrm{~cm}^{-1}$ present in $\mathrm{Hf}-\mathrm{Si} 8-\mathrm{B}$ and C, likely too weak to be observed in $\mathrm{Hf}-\mathrm{Si}$ - $\mathrm{A}$, is associated to hydrogen-bonded pyridine (weak Brønsted acidity). Indeed, the shoulder at the right side of the $1445 \mathrm{~cm}^{-1}$ band in compounds $\mathrm{Hf}-\mathrm{Si}-\mathrm{B}$ and $\mathrm{C}$, not present in $\mathrm{Hf}-\mathrm{Si} 8-\mathrm{A}$, (Figure $5 \mathrm{~B}$ and $5 \mathrm{C}$ ) likely arises from this overlapping of hydrogen bonded and Lewis acid bonded pyridine in this region. On the other hand, bands at 1610 and $1635 \mathrm{~cm}^{-1}$, both present in the three samples, are attributed to Lewis acid and strong Brønsted acid sites, respectively. ${ }^{[18]}$ On a qualitative basis, it was clear that $\mathrm{Hf}-\mathrm{Si}$ - $\mathrm{A}$, the cryogel prepared in $\mathrm{EtOH}$, had a negligible pyridine band for hydrogen bonding acid sites (combined bands at 1598 and $1445 \mathrm{~cm}^{-1}$ ), whereas the band at $1539 \mathrm{~cm}^{-1}$ was more intense and therefore indicated abundance of strong Brønsted acid sites.

In contrast, FTIR spectra of pyridine adsorbed on Hf-Si8-B and $C$ displayed intense bands corresponding to combination

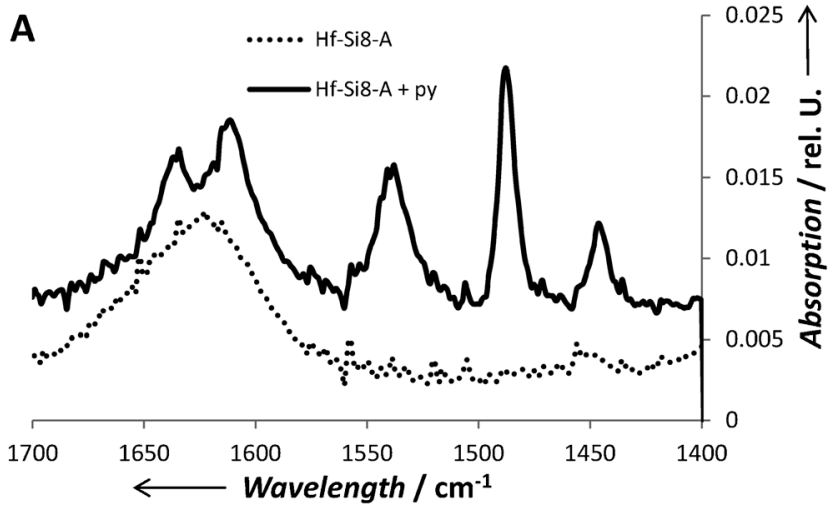

B
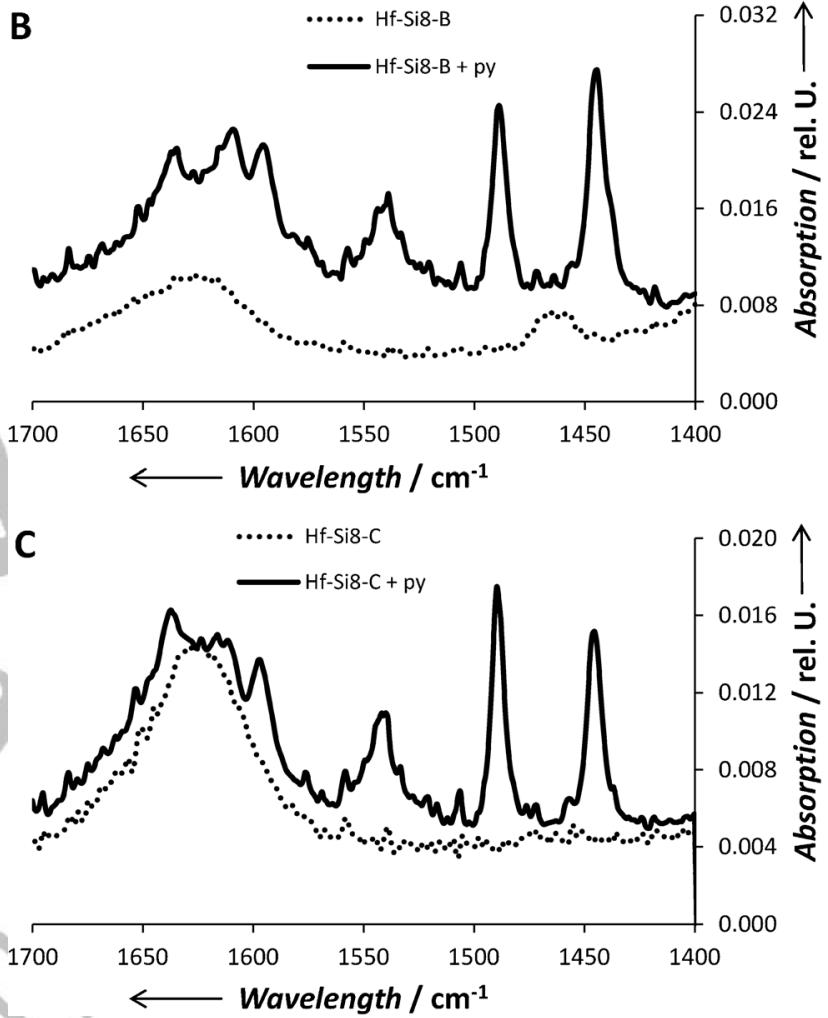

Figure 5. Pyridine (py) adsorption FTIR spectra for cryogels A) Hf-Si8-A, B) Hf-Si8-B, and C) Hf-Si8-C.

of hydrogen bonding and Lewis acid sites, besides the signals associated to Brønsted acidity. With these data, we can conclude that higher diastereoselectivity can be ascribed to those catalysts with abundance of hydrogen bonding. We suggest that the combination of Lewis acidity and hydrogen bonding facilitates the binding of the substrate, its activation, and the hydrogen transfer required by the carbonyl-ene reaction taking place. ${ }^{[19,20]}$ The large SSA and high porosity of such catalysts might provide a greater number of accessible $\mathrm{Hf}(\mathrm{IV})$ sites with coordination vacancies and the formation of weaker Brønsted acid sites.

Alternatively, thermogravimetric analysis (TGA) of this series of cryogels before and after pyridine adsorption revealed that $\mathrm{Hf}-\mathrm{Si} 8-\mathrm{A}$ had adsorbed $2.0 \mathrm{wt}$ \% pyridine, whereas Hf-Si8-B had adsorbed $5.1 \mathrm{wt} . \%$ and $C$ up to $9.7 \mathrm{wt} . \%$. This result is in good agreement with the increase of SSA along this series of 
catalysts (see Table 1), and suggests again that the number of (catalytically active) acid sites is dependent on the SSA of the catalyst.

It is not possible to distinguish the loss of adsorbed pyridine on a variety of acid sites from the dehydration of $\mathrm{Hf}-\mathrm{OH}$ or $\mathrm{Si}-$ $\mathrm{OH}$ bonds, and, therefore, the comparison of samples with adsorbed pyridine with their blanks is mandatory. Samples had to be heated up to $1000^{\circ} \mathrm{C}$ for baseline stabilization and assurance of complete loss of pyridine. ${ }^{[20,21]}$ TGA data for Hf-Si8-A with adsorbed pyridine showed that little weight loss took place over a long range of temperatures $\left(\approx 80-470^{\circ} \mathrm{C}\right) \mathrm{com}$ pared to the blank, and only at higher temperatures these samples eventually lost more weight than the blank (Figure $6 \mathrm{~A}$ ). We think that this behavior can be explained in terms of the higher Brønsted acidity of Hf-Si8-A, which retains pyridine much more strongly (likely because of the protonation) and therefore diminishes weigh loss until higher temperatures
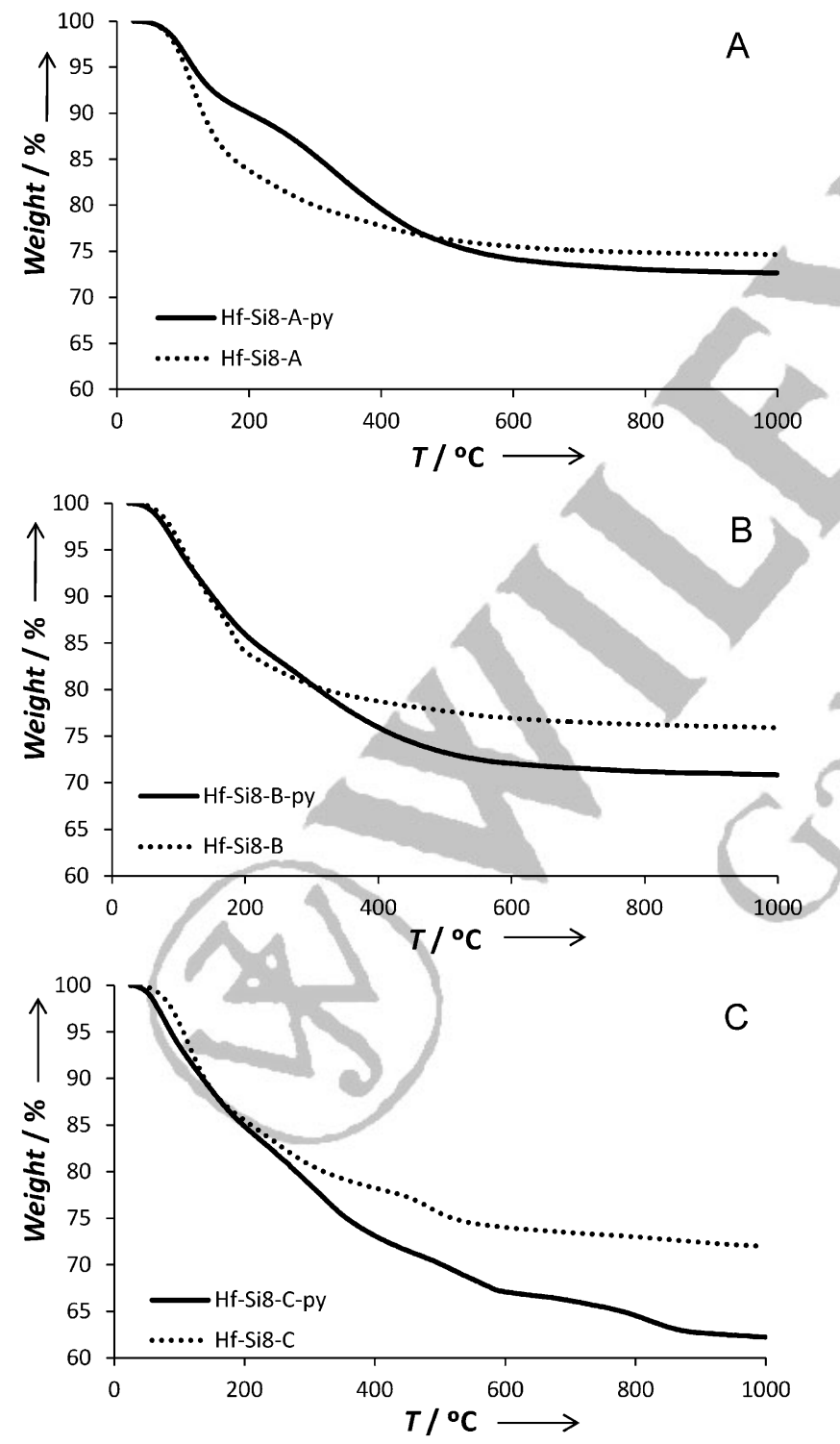

Figure 6. TGA of A) Hf-Si8-A, B) Hf-Si8-B, and C) Hf-Si8-C with (bold line) and without (dotted line) adsorbed pyridine. are reached. On the contrary, $\mathrm{Hf}-\mathrm{Si}$ - $\mathrm{B}$ with adsorbed pyridine (Figure 6B) lost weight easily at low temperatures (up to $125^{\circ} \mathrm{C}$ ), then exhibited a slight steady decrease in weight loss up to $310^{\circ} \mathrm{C}$ relative to the blank experiment $\square$ sentence ok? 口. Finally, the weight loss of Hf-Si8-C with adsorbed pyridine is clearly easier but takes place over a long range of temperatures, which suggests a wide variety of adsorption sites for pyridine (Figure $6 \mathrm{C}$ ). Plots of the subtraction of the blank from the sample data, from which changes caused by the pyridine desorption can be appreciated, are placed in the Supporting Information.

Pyridine acts as a thermodynamic probe able to recognize the acidic sites of the cryogels, but it does not give information about the activity of those sites during catalysis. For this effect, kinetic probes able to react distinctly with different catalytic sites can be used. As we did in our previous research, ${ }^{[2]}$ we decided to take advantage of the established carbonyl-ene cyclization of certain enals that leads to cis or trans products depending on whether the catalyst is a Brønsted or Lewis acid, respectively. ${ }^{[17]}$ In particular, we used enal 6 as a probe and the reaction shown in Scheme 2 as acidity indicator. If cryogels $\mathrm{Hf}-$ Si8- $A, B$, and $C$ were used to catalyze this reaction (see Table 3), Hf-Si8-A yielded predominantly the cis diastereomer

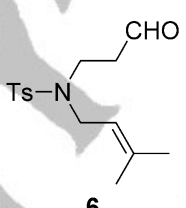

6

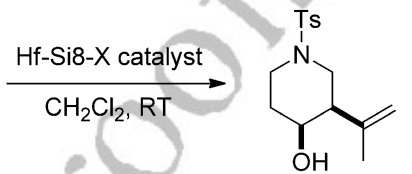

$( \pm)$-cis-7

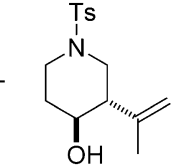

(土)-trans-7
Scheme 2. Carbonyl-ene reaction used to test catalyst acidity. Ts $=\mathbf{D}$ Tosyl a.

Table 3. Results of the carbonyl-ene cyclization of 6 with $5 \mathrm{~mol} \% \mathrm{HfO}_{2}$ $\left(\mathrm{SiO}_{2}\right)_{8}$ cryogels at room temperature.

\begin{tabular}{|c|c|c|c|}
\hline Cryogel & Synthesis conditions & $\begin{array}{l}\text { Conv. }^{[a]} \\
{[\%]}\end{array}$ & cis/trans ${ }^{[a]}$ \\
\hline $\mathrm{Hf}-\mathrm{Si} 8-\mathrm{A}$ & $\mathrm{Hf}(\mathrm{OiPr})_{4} / \mathrm{EtOH}$ & $93^{[\mathrm{b}]}$ & $1.6: 1^{[\mathrm{b}]}$ \\
\hline $\mathrm{Hf}-\mathrm{Si}$-B & $\mathrm{Hf}(\mathrm{OiPr})_{4} / \mathrm{PrOH}$ & 95 & 1:1.03 \\
\hline $\mathrm{Hf}-\mathrm{Si} 8-\mathrm{C}$ & $\mathrm{Hf}(\mathrm{OiPr})_{4} / \mathrm{tBuOH}$ & 93 & $1: 1.1$ \\
\hline
\end{tabular}

(1.6:1 ratio), which confirmed its predominantly Brønsted acid character. In contrast, Hf-Si8-B and C gave a quasi-even distribution of cis and trans products, with a slight predominance of trans, and, therefore, of Lewis acidity. In any case, these results suggest that both Brønsted and Lewis acidic sites were catalytically active in a similar fashion, and, as pyridine adsorption FTIR and TGA experiments indicated before, ethanol-made HfSi8-A contained stronger Brønsted acid sites than cryogels HfSi8-B and C, for which Lewis acidity and hydrogen bonding predominated.

Why different alcohols affect to such extent the properties of cryogels may be a matter of discussion. During their prepa- 
ration, once hydrolysis of the precursors was finished, it is reasonable to think that differences in the cryogels would arise during the gelation step, rather than the hydrolysis, because gelation is the step at which the structure of the co-gels is defined. We speculate that viscosity and polarity of the solvents might have a strong influence in the outcome of the porosity and microscopic appearance, although the exact mechanism of action is unknown to us. For example, dynamic viscosities at $30^{\circ} \mathrm{C}$ of $t \mathrm{BuOH}(3.38 \mathrm{cP} ; 1 \mathrm{cP}=1 \mathrm{mPas} \square \mathrm{SI}$ unit conversion provided $\square), i \mathrm{PrOH}(1.77 \mathrm{cP})$ and $\mathrm{EtOH}(1.00 \mathrm{cP})$ follow that trend, as well as dielectric constants $(10.9,18.4$, and 23.9, respectively). ${ }^{[22]}$ However, the drying step (lyophilization) might be equally important as well, especially to preserve the structure of the gel. In this sense $t \mathrm{BuOH}$ is a most convenient solvent to minimize pore collapse an shrinkage. ${ }^{[16]}$

\section{Conclusions}

Hafnia-silica cryogels can be prepared very easily by a sol-gel method as $\mathrm{HfO}_{2}\left(\mathrm{SiO}_{2}\right)_{8}$ under a variety of conditions, but their properties are highly influenced by the alcoholic solvent used. Ethanol, isopropyl alcohol, and tert-butyl alcohol were suitable for obtaining cryogels, whereas ethylene glycol was excellent for obtaining xerogels by calcination.

More remarkably, we showed by nitrogen sorption experiments that the alcoholic solvent is also a key factor to control the micro-, meso-, and macroporosity of the cryogels, with tert-butyl alcohol as the most suitable solvent to obtain large specific surface areas and bigger pores. Furthermore, the solvent also affects the microscopic appearance of the materials. SEM analysis of the samples provided evidence that hafniasilica mixed oxides made in $\mathrm{tBuOH}(\mathrm{Hf}-\mathrm{Si} 8-\mathrm{C})$ have more roughness and contain canals and macropores, which are less evident in samples synthesized in $\mathrm{iPrOH}(\mathrm{Hf}-\mathrm{Si} 8-\mathrm{B})$ and very scarce if the cryogel was prepared in $\mathrm{EtOH}$ ( $\mathrm{Hf}-\mathrm{Si} 8-\mathrm{A})$.

These textural characteristics seem to be the key to explaining the catalytic activity of these cryogels in the citronellal cyclization to isopulegol, because a clear trend in conversion was observed following the order $\mathrm{Hf}-\mathrm{Si}$ - $\mathrm{C}>\mathrm{Hf}-\mathrm{Si}$ - $\mathrm{B}>\mathrm{Hf}-\mathrm{Si}$ - $\mathrm{A}$. This trend refers actually to reaction rates, but if taking into account the specific surface area of the catalysts to calculate turnover frequencies, it was clear that all cryogels behaved similarly, although Hf-Si8-A gave a slightly slower reaction. On the other hand, the diastereoselectivity of the reaction followed the same trend again. Pyridine adsorption FTIR and thermogravimetry experiments suggested that the more active and diastereoselective catalysts ( $\mathrm{Hf}-\mathrm{Si}$ - $\mathrm{B}$ and $\mathrm{C}$ ) contain a combination of Lewis acidic and hydrogen bonding (weak Brønsted acid) sites, whereas strong Brønsted acidic sites predominate in $\mathrm{Hf}-\mathrm{Si}$ - $\mathrm{A}$. Indeed, the use of a kinetic probe confirmed the previous results, suggesting that both types of acidic sites are similarly active in the reaction, and that the diastereoselectivity towards the trans isomer or isopulegol depends on Lewis acidity plus hydrogen bonding.

If compared with our previous $\mathrm{TiO}_{2}-\mathrm{SiO}_{2}$ and $\mathrm{ZrO}_{2}-\mathrm{SiO}_{2}$ cryogels, ${ }^{[2]}$ hafnia shows remarkable catalytic activity. It clearly surpasses titania in this particular application, and approaches the catalytic activity of zirconia, with similar diastereoselectivity, which makes $\mathrm{Hf}^{\mathrm{V}}$ a good candidate for other Lewis acid applications.

In summary, we have shown in this work how the textural properties and subsequent catalytic activity (including diastereoselectivity) of hafnia-silica cryogels can be modified by the judicious choice of solvent during their synthesis. These results are important because little is known about hafnia as catalyst. We hope that our results will contribute to the better understanding of such materials and the development of new catalytic applications. Work along this line is currently actively pursued in our laboratories.

\section{Experimental Section}

\section{Materials and methods}

TEOS was purchased from Aldrich, and hafnium(IV) tetra-isopropoxide and tert-butoxide from Strem. All reagents were used as received. Analysis or HPLC-grade absolute ethanol, isopropyl alcohol, and tert-butyl alcohol were used as solvents. Concentrated hydrochloric acid (37\%, analysis grade, from Baker) and MilliQ water $(18.2 \mathrm{M} \Omega \mathrm{cm})$ were additionally used for the preparation of mixed oxides. Anhydrous dichloromethane obtained from a solvent purification system or alumina-dried deuterochloroform were used for the carbonyl-ene reactions.

Powder X-ray analyses were performed on a PANalytical X'Pert PRO MPD Alpha1 powder diffractometer (at Servei de Difracció de Raigs- $X$ from Centres Científics i Tecnològics de la Universitat de Barcelona) in Bragg-Brentano $\theta / 2 \theta$ geometry of 240 millimeters of radius using $\mathrm{CuK}_{\alpha 1}$ radiation $(\lambda=1.5406 \AA)$, a work power of $45 \mathrm{kV}$ $40 \mathrm{~mA}$, and a focalizing Ge (111) primary monochromator. SEM images were recorded with a Hitachi TM-1000 microscope, operated at $15 \mathrm{kV}$. Samples were coated by sputtering with gold. Nitrogen sorption experiments were performed in a Quantachrome Autosorb-IQ automated gas sorption apparatus. Samples were degassed at $80^{\circ} \mathrm{C}$ for $24 \mathrm{~h}$ before the experiments, and $\mathrm{N}_{2}$ sorption isotherms were recorded at $-196^{\circ} \mathrm{C}$. This characterization has been performed by the Nanostructured Liquid Characterization Unit of the Spanish National Research Council (CSIC) and the Biomedical Networking Center (CIBER-BBN), located at IQAC-CSIC. NMR analyses were also performed in-house in an automated Varian VNMRS $400 \mathrm{MHz}$ equipped with a One NMR Probe. $\mathrm{CDCl}_{3}$ was used as solvent and reference. FTIR spectra were recorded in a Nicolet Avatar 360 apparatus equipped with an ATR add-on.

\section{Synthesis of $\mathrm{HfO}_{2}\left(\mathrm{SiO}_{2}\right)_{8}$ cryogels}

$\mathrm{HfO}_{2}\left(\mathrm{SiO}_{2}\right)_{8}$ co-gels were synthesized by adding a solution of Hf$(\mathrm{OiPr})_{4} \cdot \mathrm{PrOH}$ or $\mathrm{Hf}(\mathrm{OtBu})_{4} \cdot \mathrm{tBuOH}(2 \mathrm{mmol})$ in TEOS $(3.6 \mathrm{~mL}$, $16 \mathrm{mmol}$ ) and a certain amount of alcoholic solvent $(70 \mathrm{mmol})$ to a vigorously stirred $(1000 \mathrm{rpm})$ solution of $1.4 \mathrm{M}$ aqueous hydrochloric acid (equivalent to $450 \mathrm{mmol}$ of water), and alcohol $(200 \mathrm{mmol})$. The mixture was hydrolyzed for $24 \mathrm{~h}$, then transferred to closed bottles and heated at $80^{\circ} \mathrm{C}$ for another $24 \mathrm{~h}$. The co-gels obtained were frozen at $-80^{\circ} \mathrm{C}$, and then lyophilized. The final cryogels were ground to a fine powder. 


\section{Catalytic cyclization of citronellal}

Hf-Si8-X catalyst $(19.2 \mathrm{mg}, 5 \mathrm{~mol} \% \mathrm{Hf}$ with respect to citronellal) was weighed into a flame-dried flask, and purged with nitrogen. Anhydrous dichloromethane $(2 \mathrm{~mL})$ was added by a syringe. Then, citronellal $(100 \mu \mathrm{L}, 0.556 \mathrm{mmol})$ was added, and the mixture was stirred at RT for $20 \mathrm{~h}$. The suspension was filtered through a pad of Celite 545 and washed thoroughly with $\mathrm{CH}_{2} \mathrm{Cl}_{2}$. After solvent removal in vacuo, the crude product was analyzed by ${ }^{1} \mathrm{H}$ NMR spectroscopy to determine conversion and diastereoselectivity by integration of the characteristic signals. ${ }^{[23]}$

\section{Pyridine adsorption}

$\mathrm{Hf}-\mathrm{Si} 8 \mathrm{-X}(50 \mathrm{mg})$ were weighed into a flame-dried Schlenk flask and degassed under vacuum for $2 \mathrm{~h}$. Then, pyridine-saturated argon was flown into the sample for $2 \mathrm{~h}$, which was subsequently degassed for another $2 \mathrm{~h}$. FTIR spectra (256 scans) were recorded at $2 \mathrm{~cm}^{-1}$ resolution between $1400-1700 \mathrm{~cm}^{-1}$, and TGA were performed in alumina crucibles from 25 to $1000^{\circ} \mathrm{C}$ at $20^{\circ} \mathrm{Cmin}^{-1}$ under nitrogen flow.

\section{Acknowledgements}

Financial support comes from Ministerio de Economía y Competitividad (CTQ2012-38594-C02-02 and RYC-2010-06750). C.J. is a Ramón y Cajal fellow. Support by Prof. A. Messeguer and Prof. I. Alfonso $\square$ please provide first names $\mathbf{\square}$ is gratefully acknowledged.

Keywords: alcohols - hafnium - Lewis acids - mesoporous materials $\cdot$ sol-gel processes

[1] a) M. L. Clarke, M. B. France, Tetrahedron 2008, 64, 9003-9031; b) G. M. Pajonk, Catal. Today 1997, 35, 319-337.

[2] C. Jimeno, J. Miras, J. Esquena, Catal. Lett. 2013, 143, 616-623.

[3] M. A. Ahmed, Fuel Process. Technol. 2011, 92, 1121-1128.

[4] C. M. Lousada, M. Yang, K. Nilsson, M. Jonsson, J. Mol. Catal. A 2013, $379,178-184$.

[5] C. Lourenço, M. d. C. Michelini, J. Marcalo, J. K. Gibson, M. C. Oliveira, J. Phys. Chem. A 2012, 116, 12399-12405.

[6] a) J. H. Choi, Y. Mao, J. P. Chang, Mater. Sci. Eng. R 2011, 72, 97-136; b) M. Houssa, L. Pantisano, L. A. Ragnarsson, R. Degraeve, T. Schram, G. Pourtois, S. De Gendt, G. Groeseneken, M. M. Heyns, Mater. Sci. Eng. R 2006, 51, 37-85; C) J. Robertson, Eur. Phys. J. Appl. Phys. 2004, 28, $265-$ 291; d) J. Robertson, B. Falabretti, J. Appl. Phys. 2006, 100, 014111; e) R. M. Wallace, G.D. Wilk, Crit. Rev. Solid State Mater. Sci. 2003, 28, 231-285.

[7] a) R. R. Gonçalves, G. Carturan, M. Montagna, M. Ferrari, L. Zampedri, S. Pelli, G. C. Righini, S. J. L. Ribeiro, Y. Messaddeq, Opt. Mater. 2004, 25, 131-139; b) E. P. Kokanyan, L. Razzari, I. Cristiani, V. Degiorgio, J. B. Gruber, Appl. Phys. Lett. 2004, 84, 1880-1882; c) J. Bellum, D. Kletecka, P. Rambo, I. Smith, J. Schwarz, B. Atherton, Appl. Opt. 2011, 50, C340C348; d) O. Stenzel, S. Wilbrandt, M. Schuermann, N. Kaiser, H. Ehlers, M. Mende, D. Ristau, S. Bruns, M. Vergoehl, M. Stolze, M. Held, H. Niederwald, T. Koch, W. Riggers, P. Burdack, G. Mark, R. Schaefer, S. Mewes, M. Bischoff, M. Arntzen, F. Eisenkraemer, M. Lappschies, S. Jakobs, S. Koch,
B. Baumgarten, A. Tuennermann, Appl. Opt. 2011, 50, C69-C74; e) J. Wang, R. L. Maier, H. Schreiber, Appl. Opt. 2008, 47, C189-C192.

[8] J. Wang, H. P. Li, R. Stevens, J. Mater. Sci. 1992, 27, 5397- 5430.

[9] a) S. Gross, K. Mueller, J. Sol-gel Sci. Technol. 2011, 60, 283-298; b) L. Armelao, H. Bertagnolli, S. Gross, V. Krishnan, U. Lavrencic-Stangar, K. Muller, B. Orel, G. Srinivasan, E. Tondello, A. Zattin, J. Mater. Chem. 2005, 15, 1954-1965; c) L. Armelao, C. Eisenmenger-Sittner, M. Groenewolt, S. Gross, C. Sada, U. Schubert, T. A. Eugenio, A. Zattin, J. Mater. Chem. 2005, 15, $1838-1848$; d) L. Armelao, S. Gross, K. Mueller, G. Pace, E. Tondello, O. Tsetsgee, A. Zattin, Chem. Mater. 2006, 18, 6019-6030; e) L. Armelao, H. Bertagnolli, D. Bleiner, M. Groenewolt, S. Gross, V. Krishnan, C. Sada, U. Schubert, E. Tondello, A. Zattin, Adv. Funct. Mater. 2007, 17, $1671-1681$.

[10] a) R. B. Tokas, N. K. Sahoo, S. Thakur, N. M. Kamble, Curr. Appl. Phys. 2008, 8, 589-602; b) S. Kohli, P. R. McCurdy, C. D. Rithner, P. K. Dorhout, A. M. Dummer, C. S. Menoni, Metall. Mater. Trans. A 2011, 42, 71- 75.

[11] K. W. Terry, C. G. Lugmair, T. D. Tilley, J. Am. Chem. Soc. 1997, 119, 9745 9756.

[12] a) G. Mountjoy, M. A. Holland, P. Gunawidjaja, G. W. Wallidge, D. M. Pickup, R. J. Newport, M. E. Smith, J. Sol-gel Sci. Technol. 2003, 26, 161 164; b) L. A. O'Dell, P. N. Gunawidjaja, M. A. Holland, G. Mountjoy, D. M. Pickup, R. J. Newport, M. E. Smith, Solid State Nucl. Magn. Reson. 2008, 33, 16-24; c) T. J. Bastow, M. E. Smith, H. J. Whitfield, J. Mater. Chem. 1996, 6, 1951-1955.

[13] a) Y. Nakatani, K. Kawashima, Synthesis 1978, 147-148; b) M. Boronat, A. Corma, M. Renz in Turning Points in Solid-State, Materials and Surface Science, RSC, Cambridge, 2008, pp. 639-650; c) M. Vandichel, F. Vermoortele, S. Cottenie, D. E. De Vos, M. Waroquier, V. Van Speybroeck, J. Catal. 2013, 305, 118- 129.

[14] J. B. Miller, E. I. Ko, Catal. Today 1997, 35, 269-292.

[15] P. I. Ravikovitch, S. C. Odomhnaill, A. V. Neimark, F. Schuth, K. K. Unger, Langmuir 1995, 11, 4765-4772.

[16] A. Pons, L. Casas, E. Estop, E. Molins, K. D. M. Harris, M. Xu, J. Non-Cryst. Solids 2012, 358, 461-469.

[17] a) J. T. Williams, P. S. Bahi, B. M. Kariuki, N. Spencer, D. Philp, J. S. Snaith, J. Org. Chem. 2006, 71, 2460-2471; b) J. T. Williams, P. S. Bahia, J. S. Snaith, Org. Lett. 2002, 4, 3727-3730.

[18] a) E. P. Parry, J. Catal. 1963, 2, 371-379; b) Characterization of Solid Catalysts: Sections 3.2.3 and 3.2.4 in Handbook of Heterogeneous Catalysis (Eds.: G. Ertl, H. Knözinger, J. Weitkamp), Wiley, Weinheim, 1997; c) A. Sakthivel, S. E. Dapurkar, N. M. Gupta, S. K. Kulshreshtha, P. Selvam, Microporous Mesoporous Mater. 2003, 65, 177-187; d) E. J. M. Hensen, D. G. Poduval, V. Degirmenci, D. A. J. Mitchel Ligthart, W. Chen, F. Maugé, M. S. Rigutto, J. A. Rob van Veen, J. Phys. Chem. C 2012, 116, 21416-21429; e) Y. Matsunaga, H. Yamazaki, T. Yokoi, T. Tatsumi, J. N. Kondo, J. Phys. Chem. C 2013, 117, 14043-14050.

[19] The synergistic action of Lewis and Brönsted acid sites in the cyclization of citronellal has been suggested recently. See: S. Telalović, A. Ramanathan, J. F. Ng, R. Maheswari, C. Kwakernaak, F. Soulimani, H. C. Brouwer, G. K. Chuah, B. M. Weckhuysen, U. Hanefeld, Chem. Eur. J. 2011, 17, 2077-2088.

[20] We thank an anonimous referee for insightful comments on the pyridine adsorption FTIR and TGA.

[21] H. Matsuhashi, H. Motoi, K. Arata, Catal. Lett. 1994, 26, 325-328.

[22] in Data from the Dortmund Data Bank (DDB) and microkat.gr.

[23] P. J. Kropp, G. W. Breton, S. L. Craig, S. D. Crawford, W. F. Durland, J. E. Jones, J. S. Raleigh, J. Org. Chem. 1995, 60, 4146-4152.

Received: April 1, 2014

Revised: May 19, 2014

Published online on $\mathbf{\square}$ II, 0000 


\section{FULL PAPERS}

Alcohol affects your pores: $\mathrm{HfO}_{2}-\mathrm{SiO}_{2}$ cryogels display unprecedented catalytic activity in the citronellal cyclization to isopulegol. The alcoholic solvent used in their synthesis determines the textural and catalytic characteristics, including acidity. tert-Butyl alcohol stands up as the solvent of choice, producing materials with high specific surface area, porosity, and Lewis acidity.
ג吾O

C. Jimeno, ${ }^{*}$ J. Miras, J. Esquena

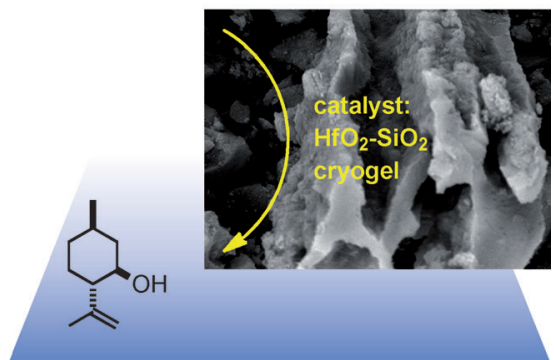

Hafnia-Silica Cryogels: SolventAssisted Textural and Catalytic Control in the Citronellal Cyclization

Want more pores? Try alcohol... Hafnia-silica cryogel \#catalyst @CSIC SPACE RESERVED FOR IMAGE AND LINK

ChemCatChem is piloting a social networking feature involving Twitter, an online microblogging service that enables its users to send and read text-based messages of up to 140 characters, known as "tweets". Please check the pre-written tweet in the galley proofs for accuracy. Should you or your institute have a Twitter account, please let us know the appropriate username (e.g., @ChemCatChem), and we will do our best to include this information in the tweet. This tweet will be posted to the journal's Twitter account upon online publication of your article.

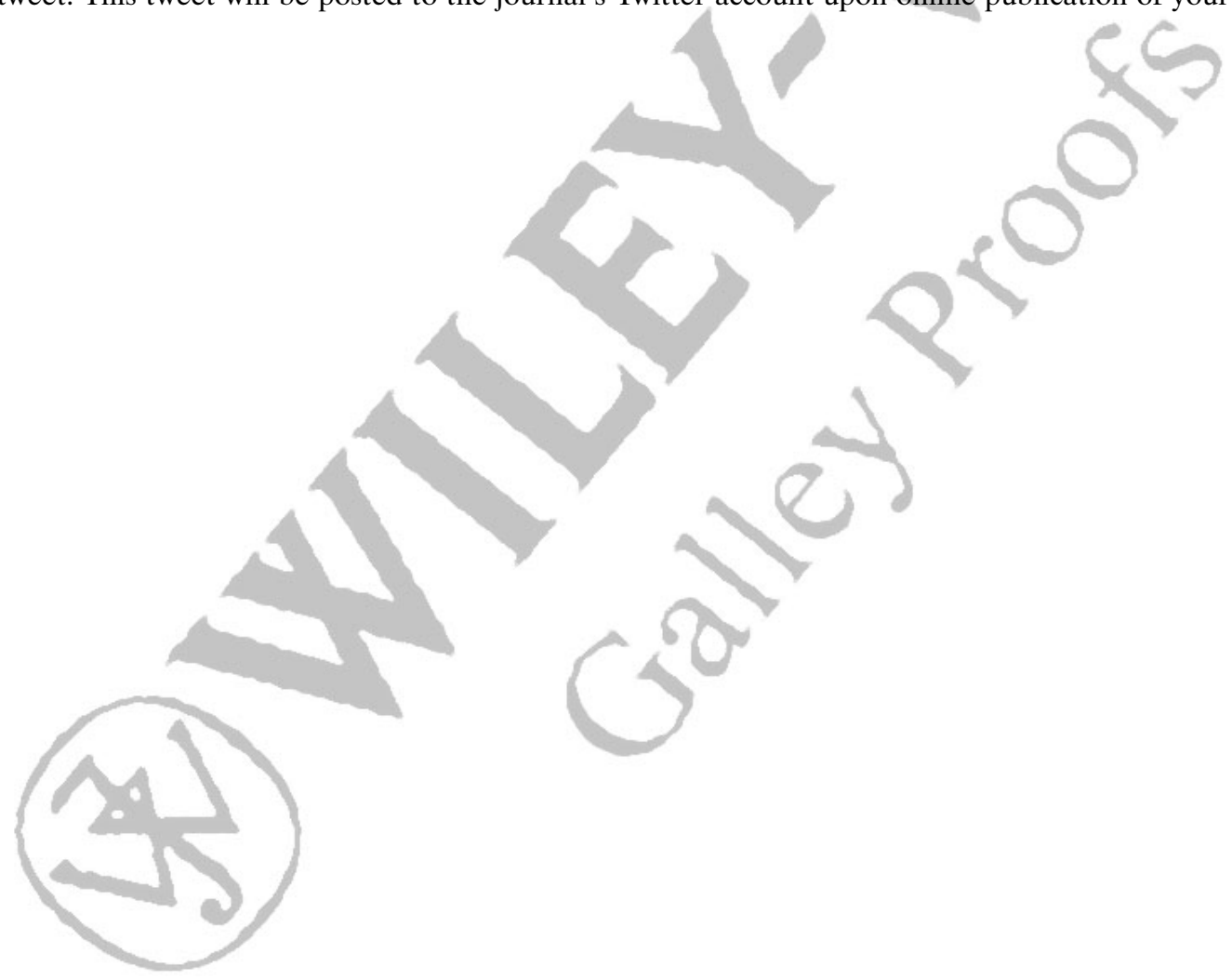

